\title{
Risk factors related to the severity of diabetic retinopathy
}

\author{
Fatores de risco relacionadosà gra vidade da retinopatia diabética
}

\author{
Zélia Maria da Silva Corrêa ${ }^{1}$ \\ André Moraes Freitas ${ }^{1}$ \\ Italo Mundialino Marcon²
}

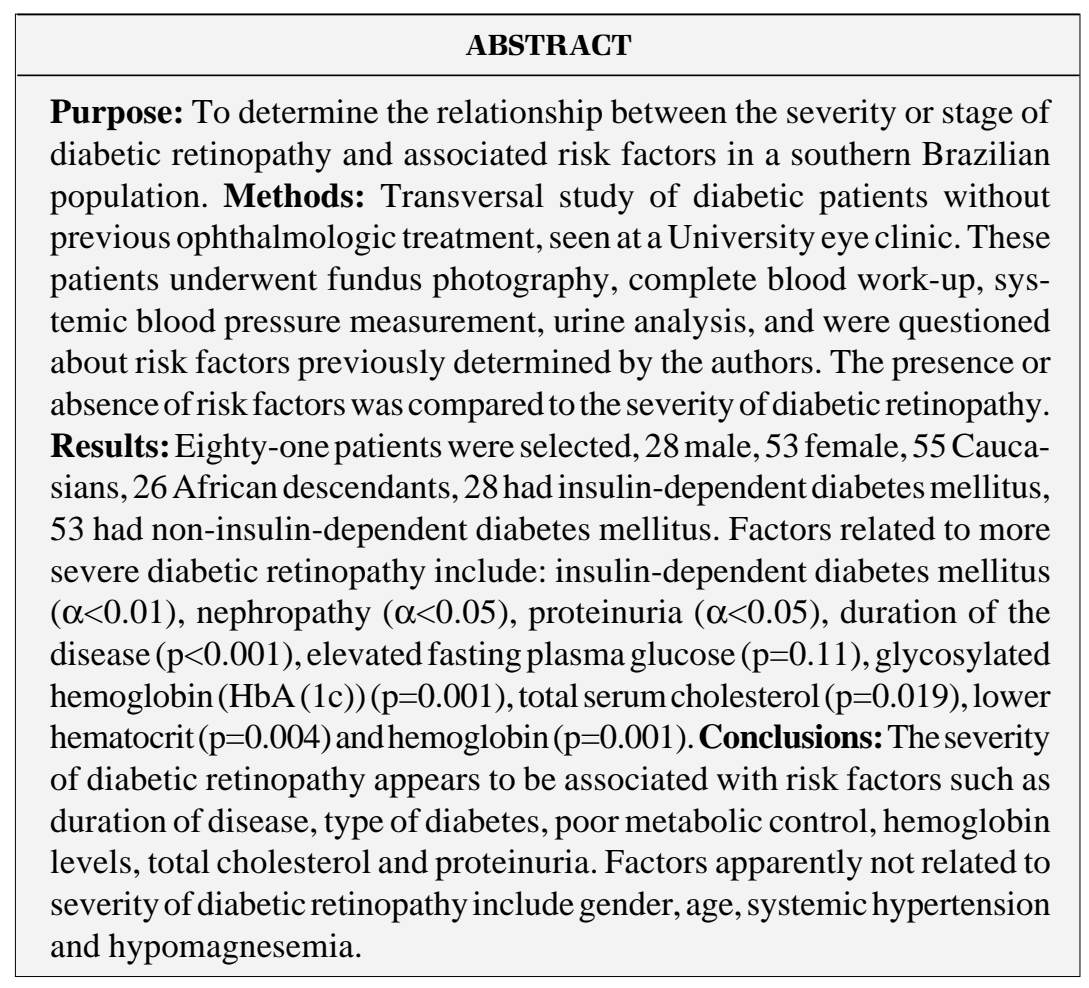

Keywords: Diabetic retinopathy; Diabetes mellitus/complications; Risk factors; Brazil/ epidemiology; Adult; Male; Female

\section{INTRODUCTION}

Diabetes mellitus is a complex metabolic disease caused by a variable interaction between hereditary and environmental factors. The clinical syndrome is defined by hyperglycemia, microvascular abnormalities (retinal and renal) and neuropathy ${ }^{(1)}$. Its main features are abnormal insulin secretion, high levels of blood glucose and a variety of complications such as nephropathy, retinopathy, neuropathy and arteriosclerosis.

Diabetic retinopathy is a leading cause of blindness in Americans between 20 and 74 years old, it is responsible for $12 \%$ of all new cases of blindness every year ${ }^{(2-3)}$. The prevalence of diabetic retinopathy has been reported from 18 to $40 \%$ depending on the population studied ${ }^{(4)}$. Authors estimate that 1 to $3 \%$ of the world's population has diabetes ${ }^{(1-2)}$. Approximately $85 \%$ of all cases present in patients 40 years old or older and only $5 \%$ in patients younger than 20 years old. Currently there is insufficient data on diabetic epidemiology in Brazil. Papers presented at the $7^{\text {th }}$ Brazilian Congress to Prevent Blindness showed a prevalence of 1.42 to $9.77 \%$ of blind eyes due to diabetic retinopathy and its related complications ${ }^{(5)}$. 
Fundus abnormalities in diabetic patients have a progressive course, from mild retinopathy, nonproliferative, where microaneurisms are the main feature ${ }^{(6)}$, to severe proliferative disease with neovascularization of the disc, retina and iris $^{(2-3)}$.

Retinopathy in diabetic patients depends not only on carbohydrate metabolism deficiency as well as on other factors being studied ${ }^{(7)}$. There is a series of factors related to the development and progression of diabetic retinopathy; some more or less related to the severity of the disease. It is not possible to define which diabetic individuals will present retinopathy. However, it is possible to determine risk factors related to the development of retinopathy ${ }^{(5)}$, such as duration of systemic disease, poor diabetes control, insulin-dependent diabetes, dislipidemia, hypertension, alcoholism, pregnancy, associated renal disease, anemia hypomagnesemia and African descendant ${ }^{(1,8-16)}$. Some studies suggest that retinopathy progression is almost inexistent in younger-onset diabetics (less than 13 years-old). There are theories that puberty hormones might be a protection factor ${ }^{(5)}$. There is controversy about the influence of some of these factors on the progression of retinopathy.

Based on these facts, epidemiologic studies to estimate incidence, prevalence and progression of diabetic retinopathy are important to establish hypotheses of its pathogenesis, and develop strategies on preventing visual loss. These data enable appropriate medical counseling, based on evidence. Studies like these become more important if proven that risk factors for diabetic retinopathy can be avoided or, at least, controlled.

\section{PURPOSE}

To determine the relationship between the severity or stage of diabetic retinopathy and possible associated risk factors in a transversal study of diabetic patients seen at a University Eye Clinic in southern Brazil.

\section{METHODS}

The inclusion criteria for this study were: no previous treatment for the retinopathy such as photocoagulation, patients had to be older than 15 years and eyes with clear media to facilitate fundus examation and fundus photography.

All diabetic patients meeting the inclusion criteria were enrolled at the Resident's Eye Clinic in Porto Alegre, Brazil. All patients were informed about the purpose of this investigation and signed an informed consent prior to enrolment in this study.

The ophthalmic evaluation consisted of corrected visual acuity and intraocular pressure measurements followed by slit lamp examination. All fundus examinations and fundus photographs were performed by the first author, using an indirect ophthalmoscope Keeler-All pupil (Keeler Instruments, Inc.,
Broomal, PA, USA) and retinal camera, Topcon 50-IA (Topcon Medical Systems, Paramus, NJ, USA) after pupil dilation using $10 \%$ tropicamide $\left(\right.$ Mydriacyl $^{\circledR}$ ).

Patients were classified in to 4 groups according to the increase severity of diabetic retinopathy adaptated from the published criteria by the Early Treatment Diabetic Retinopaty Research Group (ETDRS) $)^{(17)}$.

- Group 1: Very mild-to-mild nonproliferative diabetic retinopathy (NPDR) with findings such as microaneurisms and/or intraretinal hemorrhages and hard exudates. Diabetic patients without fundus abnormalities were included in this group for statistical purposes.

- Group 2: Moderate nonproliferative diabetic retinopathy (NPDR) with findings such as microaneurisms and/or intraretinal hemorrhages mild to moderate in all 4 quadrants or severe in less than 4 quadrants plus hard exudates and cotton-wool spots.

- Group 3: Severe to very severe nonproliferative diabetic retinopathy (NPDR) with findings suggesting risk for neovascular proliferation as intraretinal microvascular abnormalities (IRMAs), venous beading and extensive areas of retinal ischemia.

- Group 4: Proliferative diabetic retinopathy (PDR) with evidence of neovascularization and /or vitreoretinal proliferation.

The investigation of certain risk factors was determined by previous publications ${ }^{(6-18)}$. For this reason, patients were also questioned about their disease and personal characteristics: type of diabetes (insulin- or non-insulin-dependent), time interval since diagnosis, medication in use and racial ancestry. Each patient also had complete blood work-up including: fasting blood glucose, $\mathrm{HbA}(1 \mathrm{c})$, hematocrit, hemoglobin, total serum cholesterol and fractions, creatinine, plasma magnesium, 24-hour urine test and systemic blood pressure, always measured by the same nurse. These reference values are defined according to the machine and biochemical kit used for the examination. In our institution, the reference values used are as follows:

- Fasting blood sugar (glycemia) between 70 and $110 \mathrm{mg} / \mathrm{dl}$

- HbA (1c) between 4.5 and 5.7\%

- Hematocrit (males > 38 mg/dl, females > 36 mg/dl)

- Hemoglobin between 12.5 and $14.5 \mathrm{mg} / \mathrm{dl}$

- Total serum cholesterol $\leq 200 \mathrm{mg} / \mathrm{dl}$

- LDL $\leq 130 \mathrm{mg} / \mathrm{dl}$

- HDL $\leq 55 \mathrm{mg} / \mathrm{dl}$ for males and between 45 and $65 \mathrm{mg} / \mathrm{dl}$ for females

- Triglycerides $\leq 160 \mathrm{mg} / \mathrm{dl}$

- Creatinine: between 0.3 and $1.3 \mathrm{mg} / \mathrm{dl}$

- Plasma magnesium: between 1.6 and $2.4 \mathrm{mg} / \mathrm{dl}$

- Proteinuria (measured in 24-hour urine volume) $\leq 0.15 \mathrm{~g}$

High blood pressure was defined as systolic pressure $>140 \mathrm{mmHg}$ and/or diastolic pressure $>110 \mathrm{mmHg}$.

The authors investigated a possible correlation between the studied risk factors and the severity of the disease seen on 
dilated fundus examination and color stereo fundus photographs. After data collection, it seemed obvious that most patients presented very early stages of retinopathy because this is a transversal study of diabetic individuals without previous ophthalmic treatment. Keeping that in mind, patients were regrouped to optimize statistical analysis. Patients were separated in groups A and B: individuals with no signs or very mild retinopathy (group 1) were called group $A$, and those with a more defined and advanced retinopathy (groups 2, 3 and 4)

\begin{tabular}{|lc|}
\hline \multicolumn{2}{|c|}{ Table 1. Distribution of studied patients by gender } \\
Sex & Number of patients \\
Male & $28(35 \%)$ \\
Female & $53(65 \%)$ \\
Total number of patients & $81(100 \%)$ \\
\hline
\end{tabular}

\begin{tabular}{|lc|}
\hline \multicolumn{2}{|c|}{ Table 2. Distribution of studied patients by race } \\
Race & Number of patients \\
Caucasian & $55(68 \%)$ \\
African descendant & $26(32 \%)$ \\
Total number of patients & $81(100 \%)$ \\
\hline
\end{tabular}

\begin{tabular}{|lc|}
\hline \multicolumn{2}{|c|}{ Table 3. Distribuition of studied patients by type of diabetes } \\
Type of diabetes & Number of patients \\
Insulin-dependent & $28(35 \%)$ \\
Non-insulin-dependent & $53(55 \%)$ \\
Total number of patients & $81(100 \%)$ \\
\hline
\end{tabular}

\begin{tabular}{|l|}
$\begin{array}{l}\text { Table 4. Distribution of studied patients in groups of diabetic } \\
\text { retinopathy according to the ETDRS (early treatment for diabetic } \\
\text { retinopathy) }\end{array}$ \\
$\begin{array}{lr}\text { Group } & \text { Number of patients } \\
1 & 54(66.7 \%) \\
2 & 10(12.3 \%) \\
3 & 10(12.3 \%) \\
4 & 7(8.6 \%) \\
\text { Total number of patients } & 81(100 \%) \\
\text { Groups: } 1=\text { without fundus abnormalities and background diabetic retinopathy, } \\
2=\text { pre-proliferative diabetic retinopathy, 3=pre-proliferative diabetic retinopathy } \\
\text { with signs of severity, } 4=\text { proliferative diabetic retinopathy. These groups were } \\
\text { defined by the ETDRS classification. }\end{array}$ \\
\hline
\end{tabular}

\begin{tabular}{|lc|}
\hline \multicolumn{2}{|c|}{ Table 5. Distribution of patients in groups A and B } \\
Group & Number of patients \\
A & $54(66.7 \%)$ \\
B & $27(33.3 \%)$ \\
Total & $81(100 \%)$ \\
Group $A=$ patients originally from group 1 (without retinopathy or background \\
$\begin{array}{l}\text { retinopathy), group B= patients originally from groups 2, 3 and 4 (with moderate } \\
\text { to severe retinopathy). }\end{array}$ \\
\hline
\end{tabular}

were called group B. This regrouping does not compromise the value of this study and also allows relative risk calculation of the quantitative variables.

The statistical analysis of quantitative variables such as sex, race, type of diabetes (I or II), presence or absence of anemia, nephropathy (represented by the presence of proteinuria in the 24-hour urine test and/or plasma creatinine greater than $1.3 \mathrm{mg} / \mathrm{dl}$ ), isolated proteinuria and dislipidemia, used the Chi-square test $(\alpha<0.05)$. Student's t test was used to analyze quantitative data such as age, duration of disease, fasting blood sugar, glycosylated hemoglobin (HbA (1c)), hematocrit, hemoglobin, total serum cholesterol, LDL, HDL, triglycerides, systemic blood pressure, plasma creatinine, plasma magnesium and visual acuity, comparing groups A and B. All statistical analysis was performed using the Statistica Package for the Social Sciences (SPSS 8.0 for Windows ${ }^{\circledR}$, Chicago, Il, USA).

RESULTS
Eighty-one diabetic patients were selected and evaluated
after meeting the inclusion criteria. The age of patients varied
from 20 to 78 years old (average $57.91 \pm 11.09$ years). Patients'
profile data such as sex, race and type of diabetes are shown
in Tables 1 , 2 and 3, respectively.
Patient distribuition according to the diabetic retinopathy
classification in to 4 groups as defined previously considered
the eye with more advanced disease. The results are shown in
Table 4 .
For statistical purposes, patients of group 1 were named
group A, and patients of groups 2 , 3 and 4 were group B.
Consequently, group A presented patients with very mild-to-
mild retinopathy and group B presented patients with modera-
te to severe retinopathy (Table 5 ). Statistical analysis compa-
red the 2 groups with the studied risk factors.
Statistical analysis of quantitative variables such as sex,
race, type of diabetes (I or II), presence or absence of anemia,
nephropathy (represented by proteinuria and/or plasma crea-
tinine greater than 1.3 mg/dl), isolated proteinuria and dislipi-
demia used the Chi-square test ( $\alpha<0.05$ ). Stronger correla-
tions were found between severity of retinopathy (group B)
and the following variables: insulin-dependent diabetes
( $\alpha<0.01$ ), presence of nephropathy ( $\alpha<0.05$ ) and proteinuria
( $\alpha<0.05$ ). There seems to be an association between severity
of retinopathy and African descendants, however the Chi-
square test revealed a borderline value of significance ( $\alpha=$
0.053 ). Relative risk equals 0.51 with a confidence interval of
$95 \%$ between 0.28 e 0.92 . The Chi-square test could not be
used to access anemia because only 7 patients in this group
tested positive. Fisher's exact test did not show statistical
significance between anemia and the severity of retinopathy
(p = 0.21 ). Variables such as sex and dislipidemia did not
present a statistical correlation with the severity of diabetic
retinopathy ( $\alpha>0.05$ in all cases).


To analyze quantitative data such as age, duration of disease, fasting blood sugar, glycosylated hemoglobin, hematocrit, hemoglobin, LDL, HDL, total cholesterol, triglycerides, systemic blood pressure, presence of proteinuria, plasma creatinine, plasma magnesium and visual acuity, Student's t test was used comparing groups A and B. Results considered statistically significant were $\mathrm{p}<0.02$. Stronger associations were found between severity of retinopathy (group B) and longer time of diabetes ( $p<0.001)$, greater values of fasting blood sugar ( $p=0.11)$, HbA (1c) $(p=0.001)$ and total serum cholesterol ( $p=0.019$ ). The severity of diabetic retinopathy was also strongly associated with lower values of hematocrit $(\mathrm{p}=0.004)$, presence of proteinuria $(\mathrm{p}<0.05)$ and hemoglobin $(p=0.001)$. There was no statistical correlation between the severity of retinopathy and the following: age, LDL, HDL, triglycerides, high blood pressure, plasma creatinine and magnesium. Visual acuity of group B patients was considerably lower than that of patients of group A ( $<<0.001)$.

\section{DISCUSSION}

Many previously published studies, have been looking at the risk factors for development and progression of diabetic retinopathy. The duration of the disease seems to be the strongest factor associated with the development of retino-

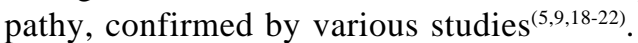

The Diabetes Clinical and Complications Trial (DCCT) evaluated the effects of rigorous control of blood sugar and concluded, in 1993, that in juvenile diabetics, intensive treatment with insulin postpones the appearance and progression of retinopathy, nephropathy and neuropathy ${ }^{(1)}$. Other studies confirm these findings in patients with type I as well as type II diabetes mellitus ${ }^{(8,18-21)}$. However it has been shown that even incipient diabetic retinopathy tends to resist arrest regardless rigorous glycemic control during a period of 5 years ${ }^{(16)}$.

Previous studies have shown a greater prevalence of proliferative retinopathy in insulin-dependent diabetics than in noninsulin-dependent diabetics. However these studies were unable to prove if this association is due to metabolic differences of the 2 types of disease, or age difference between patients and blood sugar levels usually higher in patients with type I diabetes mellitus ${ }^{(5,8)}$. The results obtained in this study are similar to previously published studies on risk factors related to the severity of diabetic retinopathy. Duration of diabetes, insulin-dependent diabetes and poor metabolic control of the disease are undoubtedly factors of great importance.

Sinav found significantly higher levels of HDL, LDL e total serum cholesterol in patients with diabetic retinopathy ${ }^{(10)}$. A similar association was found in Dornan's study, in which there was no difference in triglyceride levels between patients with proliferative retinopathy and the ones with normal fundus $^{(11)}$. The United Kingdom Prospective Diabetes Study showed no association between triglyceride levels, LDL and the progression of diabetic retinopathy ${ }^{(13)}$. In this study, total serum cholesterol appears as an important risk factor, unlike other studies that found only LDL, HDL and triglycerides to be more important risk factors for incidence and progression of diabetic retinopathy ${ }^{(10-12)}$.

Cruickshanks et al. evaluated 1139 diabetics and found an association between microalbuminuria and presence of retinopathy in these patients; this suggests an influence of nephropathy in the retinal disease ${ }^{(14)}$. Our group has published data suggesting that gross proteinuria is a risk factor for diabetic retinopathy ${ }^{(23)}$.

Anemia is considered another risk factor, perhaps because of smaller amounts of oxygen for the retinal tissue ${ }^{(24)}$. Although this study has presented a very small sample of anemic individuals $(n=7)$, low levels of hemoglobin and hematocrit, even in nonanemic individuals, seemed to be associated with the severity of diabetic retinopathy.

There are not enough studies to prove that certain ethnic groups are at greater risk to develop diabetic retinopathy. Some studies suggest that black individuals with type II diabetes have a greater prevalence of retinopathy and blindness than Caucasian individuals with the same disease $\mathrm{e}^{(5,25)}$. The prevalence of retinopathy in Japanese male diabetics appears to be smaller than in Caucasian males with type II diabetes ${ }^{(7)}$ and greater in Latins (Mexicans), regardless of their socioeconomic level ${ }^{(26)}$. However, all other risk factors seemed to have the same impact on the different racial groups ${ }^{(26)}$. In this group, individuals of African descendant appeared to have more severe diabetic retinopathy. Although our results did not show statistically significant correlation, relative risk analysis suggests a protection factor for Caucasians. The reason why this result was not statistically significant may be due to the predominance of European descendants (Caucasians) and a minority of individuals of African descendant in this area of the country.

In a study published in 1989, Hatwal et al. also listed hypomagnesemia as a risk factor for the development of diabetic retinopathy ${ }^{(27)}$. However the data provided in this study do not agree with Hatwal et al's finding. Our findings suggest that factors such as plasma magnesium, plasma creatinine, age and gender do not seem to influence the severity of diabetic retinopathy.

Klein and co-workers found that blood pressure was not a predictor of the incidence or progression of diabetic retinopathy ${ }^{(13)}$. Likewise, our study did not find any correlation between systemic hypertension and the severity of diabetic retinopathy.

Diabetic macular edema is an important cause of visual loss in diabetic patients. Lopes de Faria and co-workers have shown that adult-onset diabetes mellitus, high blood pressure, cardiovascular disease, vitreomacular adhesion and advanced diabetic retinopathy increase the risk for diabetic macular edema ${ }^{(28)}$. Although our study did not evaluate macular edema as an endpoint, our data showed that visual acuity was directly influenced by the severity of diabetic retinopathy. Also, visual acuity was decreased in individuals with advanced disease. However, systemic hypertension, as mentioned before did not seem to influence the severity of diabetic retinopathy. 


\section{CONCLUSIONS}

The severity of diabetic retinopathy in the studied group was influenced by factors such as duration of disease, type of diabetes, good glycemic control, hematocrit and hemoglobin levels, total serum cholesterol and nephropathy. Factors that apparently did not increase the risk for diabetic retinopathy were age, gender, systemic hypertension and hypomagnesemia.

\section{ACKNOWLEDGEMENTS}

The authors would like to acknowledge the valuable help of Mario Wagner, M.D., Ph.D., with the statistics of this manuscript.

\section{RESUMO}

Objetivo: Determinar a relação entre a gravidade ou estágio da retinopatia diabética e os fatores de risco associados em uma população do sul do Brasil. Métodos: Estudo transversal de pacientes diabéticos, sem tratamento oftalmológico prévio, atendidos em serviço de oftalmologia terciário. Estes pacientes foram submetidos a retinografia colorida, exames laboratoriais, medida da pressão arterial sistêmica e interrogados quanto a fatores de risco previamente estipulados pelos autores. A presença, ou ausência, de fatores de risco foi correlacionada a gravidade da retinopatia diabética. Resultados: Foram selecionados 81 pacientes, 28 homens, 53 mulheres, 55 brancos, 26 negros, 28 com diabete melito insulino-dependente, 53 com diabete melito não insulino-dependente. Fatores correlacionados estatisticamente com estágios mais avançados da retinopatia diabética incluem: dependência à insulina $(\alpha<0,01)$, nefropatia $(\alpha<0,05)$, proteinúria $(\alpha<0,05)$, maior tempo de doença $(\mathrm{p}<0,001)$, valores elevados de glicemia de jejum $(\mathrm{p}=0,11)$, hemoglobina glicosilada $(\mathrm{p}=0,001)$, colesterol total $(p=0,019)$ e valores mais baixos de hematócrito $(p=0,004)$ e hemoglobina ( $p=0,001)$. Conclusões: Concluiu-se que, neste grupo estudado, a gravidade de retinopatia diabética sofreu influência de fatores de risco como tempo de duração da doença, tipo de diabete, controle metabólico da doença, níveis de hematócrito e hemoglobina, colesterol total e proteinúria. Fatores que não pareceram influenciar a gravidade da retinopatia incluem idade, sexo, hipertensão arterial e magnésio plasmático. Tais dados são semelhantes à maioria dos estudos publicados na literatura.

Descritores: Retinopatia diabética; Diabetes mellitus/complicações; Fatores de risco; Brasil/epidemiologia; Adulto; Masculino; Feminino

\section{REFERENCES}

1. The effect of intensive treatment of diabetes on the development and progression of long-term complications in insulin-dependent diabetes mellitus. [The Diabetes Control and Complications Trial Research Group]. N England J Med 1993;329:977-86.
2. Olk RJ, Lee CM. Diabetic retinopathy: practical management. Philadelphia: Lippincott Company;1993. p.1-39.

3. Dorchy H. Characterization of early stages of diabetic retinopathy. Diabetes Care 1993;16:1212-4.

4. Kanski J. Diabetic Retinopathy. In: Kanski J. Clinical ophthalmology, Oxford, Auckland: Butterworth-Heinemann;1994. p.344-57.

5. Souza EC, Esteves JF, Broilo VR, Domingues CG, Lavinsky J. Retinopatia diabética não proliferativa. In: Abujamra S, Ávila M, Barsante C, Farah ME, Gonçalves JOR, Lavinsky J, et al, editores. Retina e vítreo: clínica e cirurgia. São Paulo: Rocca;2000. p.485-99.

6. Kohner EM, Aldington SJ, Stratton IM, Manley SE, Holman RR, Matthews DR, et al. United Kingdom Prospective Diabetes Study, 30: diabetic retinopathy at diagnosis of non-insulin-dependent diabetes mellitus and associated risk factors. Arch Ophthalmol 1998;116:297-303.

7. Araki A, Ito H, Hattori A, Inoue J, Sato T, Shiraki M, Orimo H. Risk factors for development of retinopathy in elderly Japanese patients with diabetes mellitus. Diabetes Care 1993;16:1184-6.

8. Zhang L, Krzentowski G, Albert A, Lefebvre PJ. Risk of developing retinopathy in diabetes control and complications trial type 1 diabetic patients with good or poor metabolic control. Diabetes Care 2001;24:1275-9.

9. Okada S, Ichiki K, Tanokuchi S, Hamada H, Matsuo N, Ota Z. Factors related to the development and progression of diabetic retinopathy in patients with type 2 diabetes. J Int Med Res 1996;24:214-20.

10. Sinav S, Onelge MA, Onelge S, Sinav B. Plasma lipids and lipoproteins in retinopathy of type I (insulin-dependent) diabetic patients. Ann Ophthalmol 1993;25:64-6.

11. Dornan TL, Carter RD, Bron AJ, Turner RC, Mann JI. Low density lipoprotein cholesterol: an association with the severity of diabetic retinopathy. Diabetologia 1982;22:167-70.

12. Klein BE, Klein R, Moss SE. Is serum cholesterol associated with progression of diabetic retinopathy or macular edema in persons with younger-onset diabetes of long duration? Am J Ophthalmol 1999;128:652-4.

13. Klein R, Klein BE, Moss SE, Davis MD, DeMets DL. Is blood pressure a predictor of the incidence or progression of diabetes retinopathy? Arch Intern Med 1989;149:2427-32.

14. Cruickshanks KJ, Ritter LL, Klein R, Moss SE. The association of microalbuminuria with diabetic retinopathy. The Wisconsin Epidemiologic Study of Diabetic Retinopathy. Ophthalmology 1993;100:862-7.

15. Qiao Q, Keinanen-Kiukaanniemi S, Laara E. The relationship between hemoglobin levels and diabetic retinopathy. J Clin Epidemiol 1997;50:153-8.

16. Engerman RL, Kern TS. Progression of incipient diabetic retinopathy during good glycemic control. Diabetes 1987;36:808-12.

17. Early treatment diabetic retinopathy study design and baseline patient characteristics. ETDRS report number 7. Ophthalmology 1991;98(5Suppl):741-56.

18. Klein R, Klein BE, Moss SE, Cruickshanks KJ. The Wisconsin Epidemiologic Study of Diabetic Retinopathy. XIV. Ten-year incidence and progression of diabetic retinopathy. Arch Ophthalmol 1994;112:1217-28.

19. McCance DR, Hadden DR, Atkinson AB, Archer DB, Kennedy L. Long-term glycaemic control and diabetic retinopathy. Lancet 1989;2:824-8.

20. Porto M, Sjoelie AK, Chaturvedi N, Stevens L, Rottiers R, Veglio M, Fuller JH. EURODIAB Prospective Complications Study Group. Risk factors for progression to proliferative diabetic retinopathy in the EURODIAB Prospective Complications Study. Diabetologia 2001;44:2203-9.

21. Frank RN. Etiologic mechanisms in diabetic retinopathy. In: Ryan SJ, editors. Retina. Philadelphia: Mosby;1994. p.1243-76.

22. Maberley DA, King W, Cruess AF, Koushik A. Risk factors for diabetic retinopathy in the Cree of James Bay. Ophthalmic Epidemiol 2002;9:153-67.

23. Freitas AM, Corrêa ZMS, Marcon IM, Schmidt H. Proteinúria como fator de risco para retinopatia diabética. Arq Bras Oftalmol 2002;65:83-7.

24. Klein R, Klein BE, Moss SE, Davis MD, DeMets DL. Glycosylated hemoglobin predicts the incidence and progression of diabetic retinopathy. JAMA 1988;260:2864-71.

25. Rabb MF, Gagliano DA, Sweeney HE. Diabetic retinopathy in blacks. Diabetes Care 1990;13:1202-6.

26. Haffner SM, Mitchell BD, Moss SE, Stern MP, Hazuda HP, Patterson J, et al. Is there an ethnic difference in the effect of risk factors for diabetic retinopathy? Ann Epidemiol 1993;3:2-8.

27. Hatwal A, Gujral AS, Bhatia RP, Agrawal JK, Bajpai HS. Association of hypomagnesaemia with diabetic retinopathy. Acta Ophtalmol (Copenh) 1989; 67:714-6.

28. Lopes de Faria JM, Jalkh AE, Trempe CL, McMeel JW. Diabetic macular edema: risk factors and concomitants. Acta Ophthalmol Scand 1999;77:170-5. 